\title{
Isotopes revealing the lead contamination source in the groundwater of an industrial area, São Paulo, Brazil
}

\author{
Veridiana Martins', Higor Tadeu da Silva², Ana \\ PAULA QUEIROZ ${ }^{3}$ \\ Geosciences Institute, University of São Paulo, Brazil - \\ veridian@usp.br \\ ${ }_{2}^{2}$ Waterloo Brasil Environmental Consulting - \\ higor.silva@waterloo.com.br \\ Waterloo Brasil Environmental Consulting - \\ ana.queiroz@waterloo.com.br
}

Lead and water isotopes were used to identify the source of lead contamination in groundwater at an industrial area. Some monitoring wells were presenting lead concentrations between 10,6 and $115 \mathrm{ug} / \mathrm{L}$. The brazilian legal limit is $10 \mathrm{ug} / \mathrm{L}$, above this value the area are considered contaminated and needs monitoring and remediation actions. The area belongs to a company that produces dishwashing sponges and one of the hypothesis was that lead in groundwater came from burried (at $50 \mathrm{~cm} \mathrm{bgl}$ ) leftovers from the production line. Within this scenario, this work sampled four monitoring wells (PM-02, PM-15, PM19 and PM-33), that presented different lead concentration; four sediments recovered from a soil survey profile of 15 meters depth, located near the monitoring well with the highest lead concentration values (PM-33); and dishwashing sponges. $\mathrm{H}$ and $\mathrm{O}$ isotopes were measured in the water samples using a Picarro laser spectroscope. Lead isotopes were measured in groundwater, soil/sediment and sponge samples (leaching method using EPA 3050B method and bulk dissolution of the residue for solid samples), using a TIMS Triton Mass Spectrometer, after $\mathrm{Pb}$ purification through ion exchange columns. Stable isotopes of $\mathrm{H}$ and $\mathrm{O}$ showed that PM-33 is more depleeted in heavy isotopes than the others and that PM-02 and PM-15 have similar isotope signatures. Lead isotopes in groundwater also indicated that PM-33 has a different signatures from the other wells, being more radiogenic. The other wells have similar signature. For soils/sediment and sponges analyses, results of residues revealed that the lead isotopes signatures for these sample are very different from groundwater signatures. The leaching results are less radiogenic than groundwater samples, but revealed that the highest lead concentration in groundwater has similar isotopic signature of the highest lead concentration soil. Results showed that there are different sources of lead and the most important source is soil/sediment at 8-15 mbgl. Sponges are not the lead source. 